\title{
The Gender Citation Gap in International Relations
}

\author{
Daniel Maliniak, Ryan Powers, and \\ Barbara F. Walter
}

\begin{abstract}
This article investigates the extent to which citation and publication patterns differ between men and women in the international relations (IR) literature. Using data from the Teaching, Research, and International Policy project on peerreviewed publications between 1980 and 2006, we show that women are systematically cited less than men after controlling for a large number of variables including year of publication, venue of publication, substantive focus, theoretical perspective, methodology, tenure status, and institutional affiliation. These results are robust to a variety of modeling choices. We then turn to network analysis to investigate the extent to which the gender of an article's author affects that article's relative centrality in the network of citations between papers in our sample. Articles authored by women are systematically less central than articles authored by men, all else equal. This is likely because (1) women tend to cite themselves less than men, and (2) men (who make up a disproportionate share of IR scholars) tend to cite men more than women. This is the first study in political science to reveal significant gender differences in citation patterns and is especially meaningful because citation counts are increasingly used as a key measure of research's quality and impact.
\end{abstract}

To what extent-if any-are articles in international relations (IR) cited differently depending on the gender of the publication's author? ${ }^{1}$ We address this question by analyzing citation patterns in the IR literature, using data from the Teaching,

We thank Karen Alter, Tim Büthe, Peter Gourevitch, Zoltan Hajnal, Kelly Kadera, Bob Keohane, David Lake, Lisa Martin, Rose McDermott, Andrew Moravcsik, Sara Mitchell, Maya Oren, Maggie Peters, Jaime Settle, and two anonymous reviewers for invaluable comments. We also thank the Institute for the Theory and Practice of International Relations at the College of William and Mary for providing research assistance. Powers acknowledges support from the National Science Foundation Graduate Fellowship under Grant No. DGE-0718123. Supplementary materials for this article are available at http://dx.doi.org/10.1017/S00208183000209.

1. In this article we use the term gender rather than sex to refer to our male/female variable. We realize that the two terms are not synonymous, nor is gender dichotomous. We prefer to use the term gender because the coding of the author of a publication is based heavily on the pronouns an author uses to identify him- or herself. The result, however, is that we are unable to include a category for transgendered scholars. We regret this. Still, because of the fact that transgendered individuals make up such a small proportion of the total population of IR scholars, any analysis of citation patterns of articles authored by transgendered individuals would be unreliable at best.

International Organization 67, Fall 2013, pp. 889-922

(C) 2013 by The IO Foundation.

doi:10.1017/S0020818313000209 
Research, and International Policy (TRIP) project. $^{2}$ We use the TRIP project's journal article database, which catalogues articles published in the top twelve peer-reviewed IR journals over the period 1980-2006. ${ }^{3}$ The TRIP project has coded approximately 3,000 articles on twenty-six different substantive and demographic variables. Using these data, we demonstrate the existence of a persistent gender gap in citation counts: articles written by women are consistently cited less than articles written by men. This is especially true of women who have not yet earned tenure. Observable differences between male and female IR scholars-including productivity, institutional affiliation, publication venue, or epistemology — cannot account for this gap. We explore the gender citation gap further through an analysis of men and women in the network formed by citations between the articles in our sample. Using a dyadic citation data set built from the TRIP data and the Thomson Reuters Web of Knowledge (WOK) database, we show that women are also more concentrated on the periphery of the IR network, where their work is cited less often by authors of the most heavily cited work.

Taken together, these findings offer robust evidence for a gender gap in citation counts in IR. This is a cause for concern. If women in IR are systematically cited less than men in ways that do not appear to be associated with observable differences in their scholarship, and if citation counts continue to be used as a key measure of research impact, then women will be disadvantaged in tenure, promotion, and salary decisions. This article reveals this differential pattern of citation counts and offers two potential explanations for it. Our hope is that by identifying the gender gap in citations and then identifying potential reasons for it, we can begin to address and rectify it.

\section{Gender and the IR Literature}

The status of women in academia and political science has long been a topic of discussion and concern at colleges and universities across the United States. ${ }^{4}$ Women continue to be underrepresented on political science faculty, at conferences, and in peer-reviewed publications. ${ }^{5}$ Today, women are earning PhDs in polit-

2. The TRIP Project is managed by the Institute for the Theory and Practice of International Relations at the College of William and Mary. It gathers data to enable scholars to better understand the development and current state of the discipline of IR and to what extent IR research informs or is informed by the international policymaking process. For more information, see 〈http:// irtheoryandpractice.wm.edu/projects/trip//, accessed 8 May 2013.

3. The TRIP project identified the "top" journals on the basis of their impact rating. The database itself contains bibliographic data on all articles up to 2010, but articles have been systematically coded and arbitrated only through 2006.

4. See Schuck 1969; Finifter 1973; Gruberg and Sapiro 1979; and Charles and Grusky 2005.

5. See American Political Science Association (APSA) 1992; and Gruberg and Sapiro 1979. 
ical science in record numbers but are failing to earn tenure in proportion to these numbers. $^{6}$

The disproportionately low number of female faculty is potentially problematic given that the majority of undergraduate and graduate students in the United States are female. In 2010, women represented 57 percent of all students in four-year colleges and universities and 52 percent of all students in $\mathrm{PhD}$ programs. ${ }^{7}$ It is expected that by 2020, women will represent 60 percent of all students enrolled in four-year degree-granting programs. ${ }^{8}$ If colleges and universities are serious about increasing the number of tenured female faculty, especially at large research universities, they will need to understand and address why women are failing to move up the ladder at the same rate as their male counterparts. Without this, college faculty will continue to be dominated by men even as their student bodies are increasingly dominated by women.

The number of women in academia, as well as their influence, will depend in part on how often their research gets published and whether this research is then cited by other scholars. Decisions about tenure, promotion, and salary, especially at research universities, take into account not just publications but impact, which tends to be partly measured by citation counts. Although hard data do not exist, anecdotal evidence suggests that academia is weighting the influence of citation counts more over time. As one long-standing member of a top-ten political science department observed:

In thirty years ... citation counts used to be a non-issue in hiring and promotion in my department. Until about three years ago, the issue had come up literally once. I remember because it seemed so odd. Now, the social science citation index and Google Scholar citation counts are regularly raised and discussed except for starting assistant professors. ${ }^{9}$

If departments are increasingly relying on citation counts to measure impact, then at the very least they should know whether any systematic bias exists in such counts. Work in a number of other scholarly fields shows a consistent trend in gendercitation patterns between men and women. In biology, ${ }^{10}$ biochemistry, ${ }^{11}$ ecology, ${ }^{12}$ library and information science, ${ }^{13}$ and in general studies of the natural sciences, men tend to be more productive in terms of quantity, while women tend to produce higher-quality work, at least as measured by citations. ${ }^{14}$

6. See Ginther 2004; APSA 2004 and 2007; and Hesli, Lee, and Mitchell 2012.

7. US Department of Education 2011.

8. Ibid.

9. Büthe and Aggarwal 2013; not-for-attribution interview with a full professor.

10. Sonnert 1995.

11. Long 1992.

12. Symonds et al. 2006.

13. Peñas and Willett 2006.

14. Sonnert and Holton 1996. However, Slyder et al. (2011) show no difference for articles in the field of forestry and geography for scholars from ten universities. They argue that this may be the 
Do the same trends exist in IR? Copenheaver and colleagues argue that "gender differences in citation rates appear to be discipline specific, so identifying whether a difference exists within a discipline is an important factor for making fair and equitable decisions regarding the evaluation and promotion of female and male researchers." 15 Mitchell and others provide limited evidence of a gender citation gap in IR in their bibliographic analysis of articles published in International Studies Quarterly and International Studies Perspectives in $2005 .{ }^{16}$ They find that articles published by men are less likely to cite work by women than are articles published by women. On the other hand, Østby and colleagues find that gender is not a significant determinant of publication in their analysis of submission and publication rates at the Journal of Peace Research between 1983 and 2010. ${ }^{17}$ Given the conflicting findings of some of these more limited data sets, more systematic tests are needed to come to a general understanding of how author gender affects the eventual influence of a given article.

To test if a citation gap exists in IR, we looked at more than 3,000 articles published between 1980 and 2006 in twelve influential peer-reviewed IR journals. Our findings suggest that articles authored by women are cited less on average than those authored by men. They also suggest that this gap disappears as soon as women coauthor with men.

We begin our investigation with a very basic analysis of the TRIP data set. We coded all articles in the TRIP database for the gender of the author(s), grouping them into three categories: those written by one or more male authors, those written by one or more female authors, and those written by at least one author of each gender. ${ }^{18}$ A simple cross-tabulation suggests that author gender plays a significant role in determining the number of citations a given article garners after publication. Table 1 displays the average number of citations a given article received based on the gender of the author(s). Articles authored by men garnered an average of 4.8 more citations than those authored by women over the period 19802006. Given that the average number of citations per article during this time was about twenty-five, this is quite a significant difference.

There are a number of possible explanations for why this gap exists. First, men and women tend to work at different institutions. According to the 2006 TRIP

result of frequent coauthorship among men and women, a result our analysis supports. In the field of dendrochronology, Copenheaver, Goldbeck, and Cherubini (2010) find no difference between the men and women as first authors, but they also point to the role of coauthorship.

15. Copenheaver, Goldbeck, and Cherubini 2010, 128.

16. Mitchell, Lange, and Brus forthcoming.

17. Østby et al. forthcoming.

18. This coding is based first on the pronouns that the individual authors use to refer to themselves in articles or on their department website. If no pronoun is used by the individual, we looked for photographs of the individual on their department or personal website. Finally, if no pronoun usage or photo was available, we coded based on the most common gender associated with the individual. In cases where a name was not overwhelmingly associated with one gender or another, we left the gender of the article as missing data. 
survey of IR scholars, men are more likely than women to be employed by PhDgranting institutions, while women are more likely than men to be employed by liberal arts schools. ${ }^{19}$ The focus on teaching at liberal arts colleges may lead faculty to produce less research or have fewer opportunities to publicize their work at conferences and/or at seminars at other colleges or universities. It may also be the case that the research produced by faculty at liberal arts colleges could be differentially valued by the profession because of their institutional affiliations. Likewise, tenure requirements and a focus on research may generate different incentives to engage in academic debates and produce research. Because of the gender disparity in placement at liberal arts colleges, we might expect institutional affiliation to partially account for the gender divide in citation counts.

TABLE 1. Citations by gender and decade

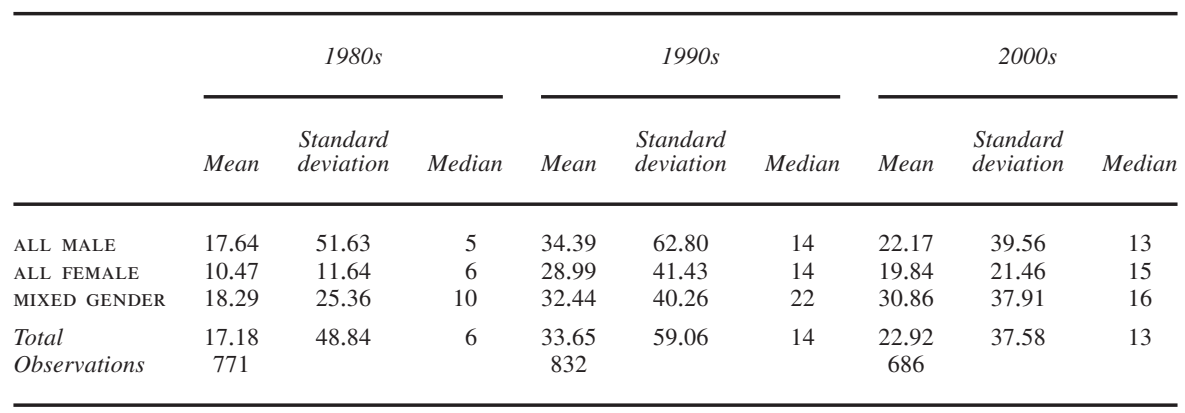

Second, women may publish less in the early years of their careers as a result of their need to take parental leave. This may not affect productivity over the long term, but if citations depend in part on building name recognition, then fewer publications early in one's career could translate into fewer citations over time. Symonds and colleagues find that discrepancies between men and women early in their careers can lead to differences in citation rates throughout their time as scholars. ${ }^{20}$ Taking a temporary leave from research in the first part of one's career, therefore, may have lasting effects.

Third, the norms of coauthorship have changed over time and differentially across genders. Fisher and others show in their analysis of coauthorship in three political science journals ${ }^{21}$ that while coauthorship across these journals has increased, it

19. The TRIP project has conducted more recent surveys, but we use the 2006 numbers in this study because that survey is coincident with the last year of publications included in our sample.

20. Symonds et al. 2006.

21. American Political Science Review, American Journal of Political Science, and Journal of Politics. 
has increased more quickly for women. ${ }^{22}$ Further, in cross-gender collaborations, they find that women are nearly four times more likely to collaborate with men than men are to collaborate with women. It is possible that women receive fewer citations because coauthors are cited less frequently or acknowledged less often than single authors or authors whose names appear first. To account for these differential coauthorship patterns, we control for coauthorship in general and whether a given instance of coauthorship is mixed gender.

Fourth, men and women tend to study different substantive issues. As Table A1 in the appendix shows, men are more likely to write articles on security, US foreign policy, and methods. Women are more likely to write articles on human rights, comparative foreign policy, health, international law, and the environment. ${ }^{23}$ If these topics are less popular and less well cited, then this could also help account for the gender gap in total citation counts.

Fifth, men and women report using different theoretical paradigms to analyze international politics. In the 2006 TRIP survey, women reported that they are more likely to employ constructivism and feminism than their male counterparts. Meanwhile, men are more likely to report employing realism or liberalism. ${ }^{24}$ Similar differences are also apparent in our data from the coded articles. Table A2 in the appendix shows this breakdown. Women are more likely than men to publish articles that are constructivist or nonparadigmatic, while men are more likely to publish articles that are atheoretic, realist, or Marxist. There is little difference in the use of liberal theory across genders. Again, if women tend to gravitate toward theoretical approaches that are less widely used and appreciated, then this could account for the lower citation rate.

Sixth, as the 2006 TRIP survey and Breuning and colleagues show, men and women tend to situate their work in different epistemological schools. ${ }^{25}$ Men are slightly more likely to report that their work is positivist. Women are nearly twice as likely as men to report their work being postpositivist. We find these trends in

22. Fisher et al. 1998.

23. These trends are reflected in APSA membership records as well. As of 2008, "APSA divisions with the lowest female representation included international security and arms control, international collaboration, foreign policy, conflict processes, and international history and politics" (Maliniak et al. 2008, 133).

24. In the 2006 TRIP survey, 29.8 percent of women reported employing feminism compared to just 16.5 percent of men. Also 7 percent of women reported being primarily committed to feminism compared to just 0.15 percent of men. By contrast, 27 percent of men reported being primarily committed to realism, compared to just 13 percent of women. Similarly 31 percent of men reported being primarily committed to liberalism compared to just 26 percent of women. The survey asked respondents, "What paradigm within international relations are you primarily committed to in your research? If you do not think of yourself as 'committed,' please pick the paradigm in which most other scholars would place your work." Respondents could choose from "Realism," "Liberalism," "Marxism," "Constructivism," "Feminism," or "Other." The 2006 TRIP survey was sent to 2,383 individuals identified as IR scholars in the United States and 275 individuals identified as IR scholars in Canada. The US and Canada samples both had a response rate of approximately 40 percent. For more details on the 2006 TRIP survey methodology, see Maliniak et al. 2007.

25. Breuning, Bredehoft, and Walton 2005. 
our data as well. We know from other recent work that articles not employing a positivist epistemology tend to be cited less, especially in the sampling of journals we include in our analysis. ${ }^{26}$

Seventh, the TRIP surveys show that women are just slightly more likely to report employing qualitative methods than are men. Conversely, men are only slightly more likely to report employing quantitative methods than women. Men are also much more likely than women to report using formal methods. ${ }^{27}$ As Maliniak and others show, quantitative and formal work are cited more frequently than qualitative work in recent years, potentially explaining the discrepancy in citations. ${ }^{28}$

Finally, it could be that the gap in citations is because of the venue in which men and women publish. Women may tend to publish in certain journals and it is these journals that tend to draw fewer citations than others. Copenheaver and colleagues, for example, find that when they control for journal-specific effects in their analysis of citations, no gender gap remains. ${ }^{29}$ It is possible that controlling for the venue in which articles are published will capture some of the variance between male and female citations.

All these explanations represent a range of plausible and compelling reasons for the citation gap in IR. Controlling for these factors, does the gender gap disappear? If not, then other less obvious factors must account for the dearth of citations that women receive.

\section{Why Citations?}

Individual citations are significant for two reasons. First, the discipline tends to use citations as an important measure of the quality of scholarly contributions, whether at the level of individual scholars, journals, or even entire institutions. Citations are one of the chief metrics used in academia to evaluate a scholar's performance and influence, and to distribute resources, including salary. ${ }^{30}$ They are also used to rate the quality of the faculty and departments across different universities. Finally, citation-related metrics are often part of efforts to evaluate institutional excellence at a global level. ${ }^{31}$ When articles are highly cited we tend to assume that they have had a significant impact on the field and that the researcher is influential. Second, the importance of citation counts is likely to increase as they become easier to compile using Google Scholar, ISI, or Scopus. If a persistent gender gap exists in citations, departments and universities should be aware of this.

26. Maliniak et al. 2008.

27. According to Maliniak et al. $(2008,136)$, "Of the 122 people in the sample who indicated that formal modeling was either their primary or secondary methodology, only 12 were women."

28. Maliniak et al. 2011.

29. Copenheaver, Goldbeck, and Cherubini 2010.

30. See Fowler and Aksnes 2007; and Dries, Pepermans, and Carlier 2008.

31. Hix 2004. 
It is important to emphasize that our analysis looks at article citations only and not the full range of venues through which scholars communicate their work. Other outlets include single and coauthored books, chapters in edited volumes, op-eds in newspapers, and (increasingly) blog posts. Given this variety, is it possible that the source of the gender citation gap is the result of self-selection into different types of publications? The evidence suggests not. Indeed, in the 2011 TRIP survey, respondents were asked to rank the "three kinds of research outputs that are most important for you to publish in order to advance your academic career." 32 A plurality of women (45.9 percent) and a large percentage of men (40 percent) listed a singleauthored journal article in a peer-reviewed journal as the most important research output to produce in order to advance their career. Coauthored articles in peerreviewed journals are also ranked in the top three, higher than any other outlet, save single-authored books for a university press and single-authored journal articles in a peer-reviewed journal. Male and female scholars seem to agree that peer-reviewed journal articles are the main currency for stature in the realm of academia. ${ }^{33}$

\section{Data}

Our universe of cases comes from the journals tracked by the TRIP project. These include American Journal of Political Science (AJPS), American Political Science Review (APSR), British Journal of Political Science (BJPS), European Journal of International Relations (EJIR), International Organization (IO), International Security (IS), International Studies Quarterly (ISQ), Journal of Conflict Resolution (JCR), Journal of Peace Research (JPR), Journal of Politics (JOP), Security Studies (SS), and World Politics (WP). For those journals that publish both IR and non-IR research, we limit our sample to those articles coded as being related to IR by TRIP.

As a dependent variable, we use the count of citations provided by the WOK. These values were gathered by an automated script in March 2013 and linked to the articles in the TRIP database by the unique combination of values formed by the title, journal of publication, issue number, and volume number. The number of citations for each article reflects citations from all articles catalogued in the WOK's Social Science Citation Index Expanded, not just those journals from which we draw our sample. ${ }^{34}$

32. Maliniak, Peterson, and Tierney 2012, 58.

33. That said, important insights could be gained from the analysis of citation patterns of other types of research output and we hope to do so in future research.

34. While Thomson Reuters does not provide an exact number of journals in their WOK database, they write on their website that the database contains more than " 12,000 top tier international and regional journals in every area of the natural sciences, social sciences, and arts and humanities." Available at $\langle$ http://wokinfo.com/publisher_relations/journals/〉, accessed 8 May 2013. 
Data for our independent variables come from the TRIP project article-coding database. ${ }^{35}$ The TRIP project has coded twenty-six variables for each article in issues one and three of each journal from 1980 to 2006. We believe the coded data are a representative sample of the IR literature over the past twenty-five years. The TRIP coding scheme records variables for important article attributes including methodology, epistemology, paradigm, time period, geographic area of study, issue area, and many others. For a more detailed description of the TRIP coding methodology, see the TRIP codebook.

Gender, our independent variable of interest, is taken from the TRIP gender variable which codes gender by the use of gendered pronouns by the author in the publication or on their website. If no gendered pronouns are used, we rely on any available photographs on the author's personal or departmental website. As a last resort, we rely on gender-specific first names. If no information about the author's gender is available, the variable is left as missing. We capture the gender makeup of a given article's authorship in three mutually exclusive dichotomous variables: all male, all female, or mixed gender.

To operationalize the potential confounding factors contributing to the gendergap in citation counts that we discussed, we use a number of specific variables from the TRIP data. These include the following:

- THEORETICAl PARAdigm. This is a nominal variable that is coded as one of the following: realist, liberal, Marxist, constructivist, nonparadigmatic, or atheoretic/none. As the TRIP codebook explains, "paradigms are defined primarily by their core assumptions and secondarily by the independent variables they emphasize." 36 See the TRIP codebook for a longer description of the paradigm coding rules.

- Age of publication. This is measured in years since publication. We add a square term to account for the possibility that the effect of age changes with time.

- AUthor TENURED. This is a dichotomous variable. An author is considered tenured if his or her rank is given as associate professor, professor, or full professor (or their equivalent for scholars at non-US institutions).

- Tenured female. This is a dichotomous variable that is coded as 1 if there is a tenured female scholar on the paper.

- R1. This is a dichotomous variable. It is coded as 1 if the author is at a "National Research University" as defined by US News and World Report's college and university rankings.

- conuthored. This is a dichotomous variable. It is coded as 1 if the publication has more than one author.

35. Peterson and Tierney 2010.

36. Ibid., 3. 
- EPISTEMology. This is a dichotomous variable. As the TRIP codebook explains, "This variable seeks to answer the question, by what criteria does the author establish knowledge claims." ${ }^{37}$ An article is coded as positivist "if [the author(s)] implicitly or explicitly assume that theoretical or empirical propositions are testable, make causal claims, seek to explain and predict phenomena, assume that research is supported by empirical means, and aspire to the use of a scientific method." 38

- ideational. This dichotomous variable captures the use of ideational factors. The TRIP codebook explains, "Any article where ideas, beliefs, perceptions, learning, norms, identity, knowledge, or personality traits play a central role in the argument, whether as independent or dependent variable, is coded as ideational."

- MATERial. This is a dichotomous variable. It is coded as 1 if the article employs "material variables," which are defined by the TRIP codebook as "non-ideational and refer to ascriptive characteristics of actors or the structures in which actors are embedded."

- ISSUE AREA. This nominal variable captures the particular subfield into which an article falls. It can take a value of any one of the following: international security, international political economy, human rights, environment, health, IR theory, US foreign policy, comparative foreign policy, history of the IR discipline, philosophy of science, international law, other, general (or nonspecific), international organization, methodology, comparative politics, American politics, or political theory. The TRIP codebook explains, "we have values for [non-IR] subfields of political science so that we can track non-IR articles in IR journals."

- Methodology. This is a set of dichotomous variables. The TRIP codebook explains that this variable is a "measure of whether the study uses quantitative (statistics), qualitative (case studies), formal modeling (calculus, game theory, spatial modeling), or some other methodological approach. Many articles utilize more than one methodology." An article can employ one or more of the following types of methods: quantitative, qualitative, formal modeling, counterfactual, analytics/nonformal conceptual, descriptive, policy analysis, and experimental.

- JOURnal of PUbliCAtion. This nominal variable takes on the value of one of the twelve journals tracked by the TRIP database.

Table A3 in the appendix provides descriptive statistics on each of these variables.

37. Ibid., 7 .

38. Ibid., 10. 


\section{Analysis}

Using the data we described, we test the extent to which each of our independent variables affects citation counts. ${ }^{39}$ Our estimates are based on a negative-binomial model because of clear overdispersion in the citation count variable. In all cases, we include our main independent variables of interest, an ALL FEMALE and a MIXED GENDER variable, with ALL MALE as the reference category. ${ }^{40}$ To account for potential idiosyncrasies across publication years in the data, we include year fixedeffects. Moreover, we exclude articles published later than 2006 so that each article has at least five years of exposure to possible citations by the time we gathered the counts. We also include the age of the article (in years) and a quadratic of age to help control both for exposure but also the changing nature of citation patterns over time.

In our baseline model in Table 2, the ALL FEMALE variable is negative and statistically significant. Given that the coefficient represents the natural log of the expected count of citations, we can interpret this as female-authored articles receiving roughly 80 percent of the citations that a similar male-authored article would receive. Articles having at least one male and one female author show no statistically significant difference in citations from male-only authored articles. Adding controls for age, in Model 2, we see unsurprisingly that older articles receive more citations than younger articles, but that this effect declines over time. The effect of article age slightly reduces the magnitude of our gender effect, but it does not affect its direction or statistical significance.

In Model 3 of Table 2, we explore the extent to which accounting for careerrelated factors helps explain the gender gap in citation counts. As noted, women in the field of IR are less likely to be employed by R1 institutions. We account for institutional affiliation by including a variable that captures whether any of the authors are employed at an R1 institution. ${ }^{41}$ In this model, R1 affiliation has a positive and significant effect on citation counts. Because we also noted how coauthorship differs across gender, we add a variable to account for whether a given article is coauthored. Coauthorship has a positive and significant effect on

39. A number of the explanations that we suggest may themselves be affected by similar gender biases to those that lead women to be cited less once their research is published. Women may choose to attend particular graduate programs, study particular topics, work at particular institutions, publish in particular journals, and get promoted at different rates as a result of subtle or overt gender-based pressures. If that is the case and these factors contribute to the citation gap, then controlling for these intermediate factors in an analysis of any potential gender bias in citations is not appropriate (King, Keohane, and Verba 1994). Since we have a strong expectation about the direction of the bias thanks to other recent literature, we include these potentially posttreatment variables to illustrate the magnitude of the gender bias more clearly. That is to say, we find a gender effect even after controlling for a wide variety of potentially posttreatment variables.

40. The results are qualitatively similar when we include only an ALL FEMALE dummy variable or a measure of the percent of authors who are female.

41. Our results are similar if we control for being a member of a top-twenty institution as defined by the most recent US News and World Report rankings of IR graduate programs. 


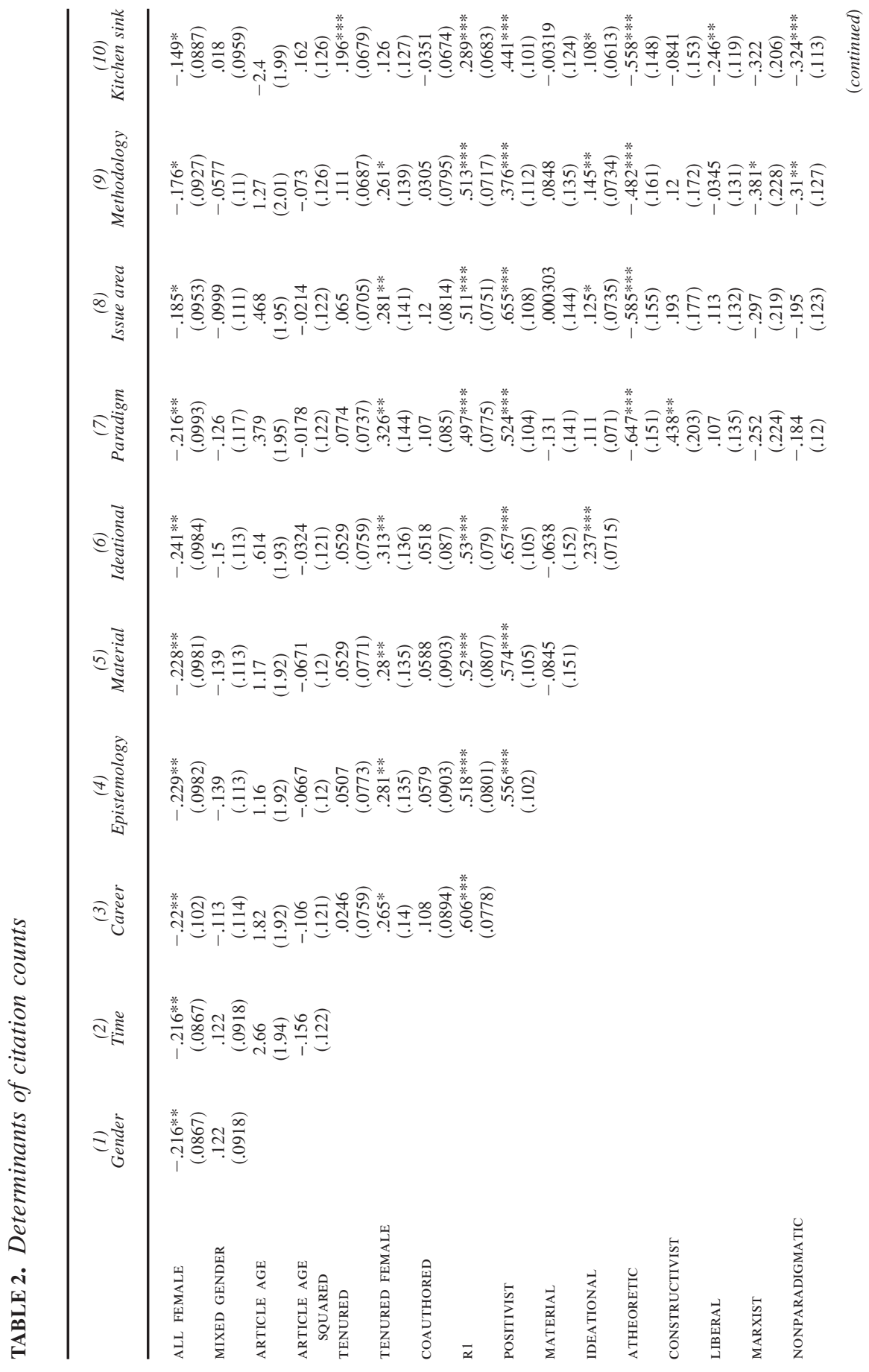




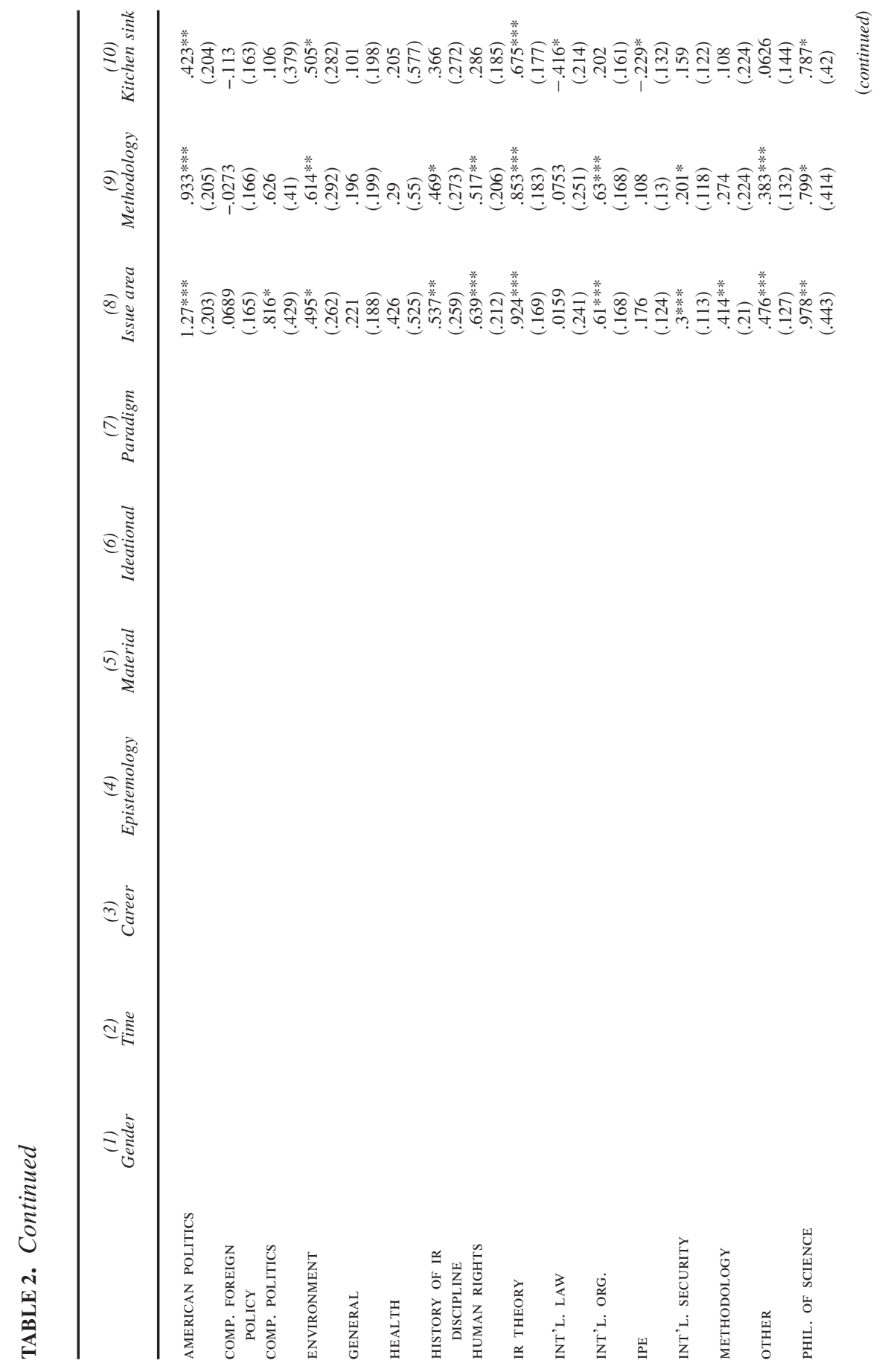




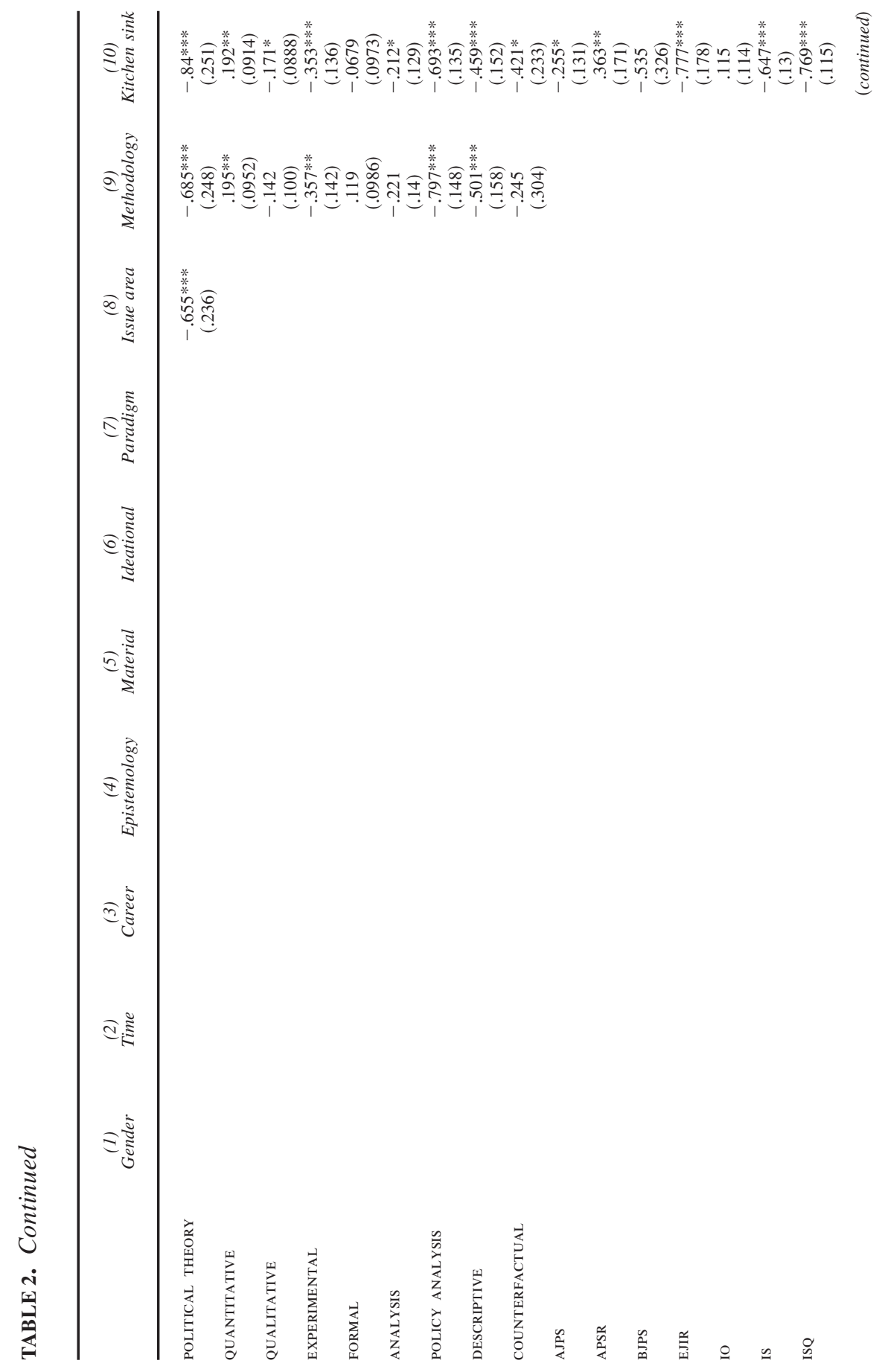




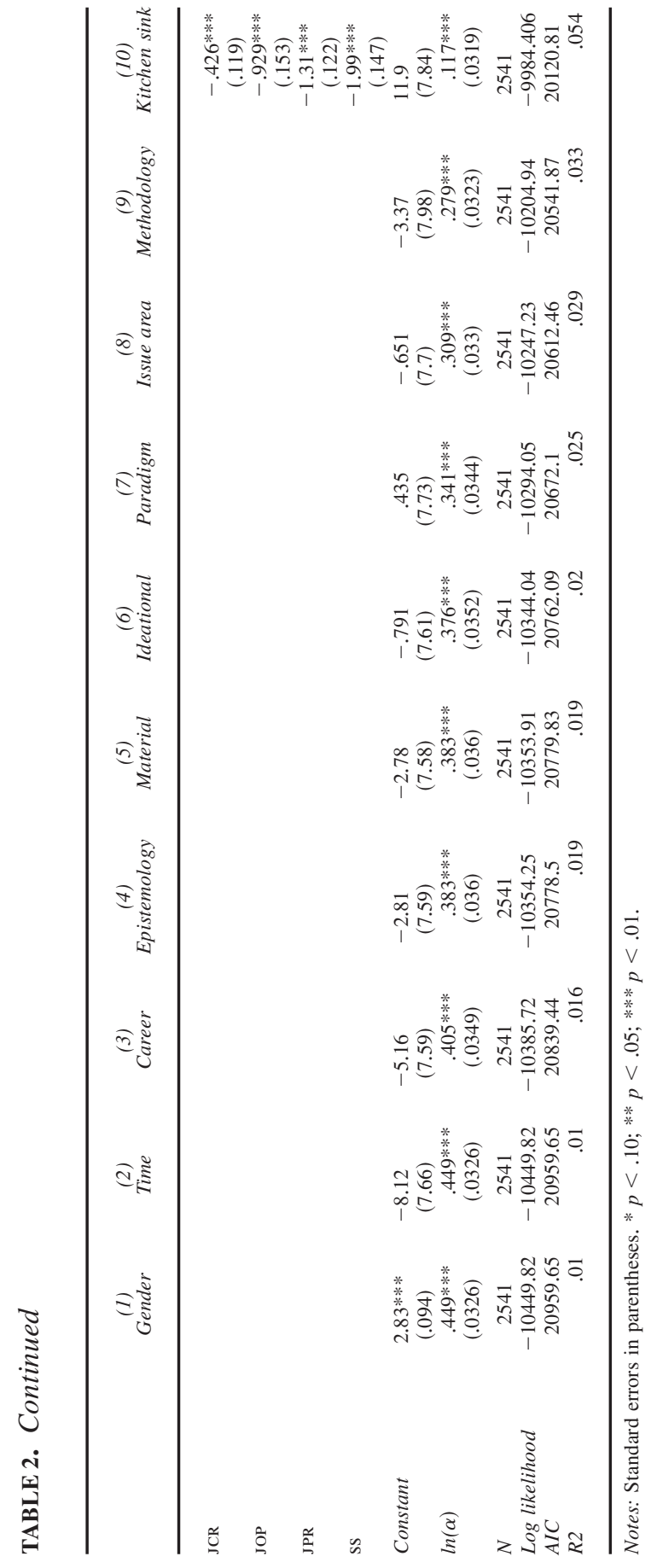


citation counts. ${ }^{42}$ We also add two variables to account for the effect of tenure across genders. The first is a simple dichotomous variable called TENURE that takes on a value of 1 if any of the authors on the article are tenured and 0 otherwise. The second is a variable called TENURED FEMALE that takes on a value of 1 if at least one of the authors on a given article is a female with tenure. Figure 1 shows the predicted count of citations and 95 percent confidence interval for all four categories of interest. Tenure is associated with more citations for both point estimates of male and female.

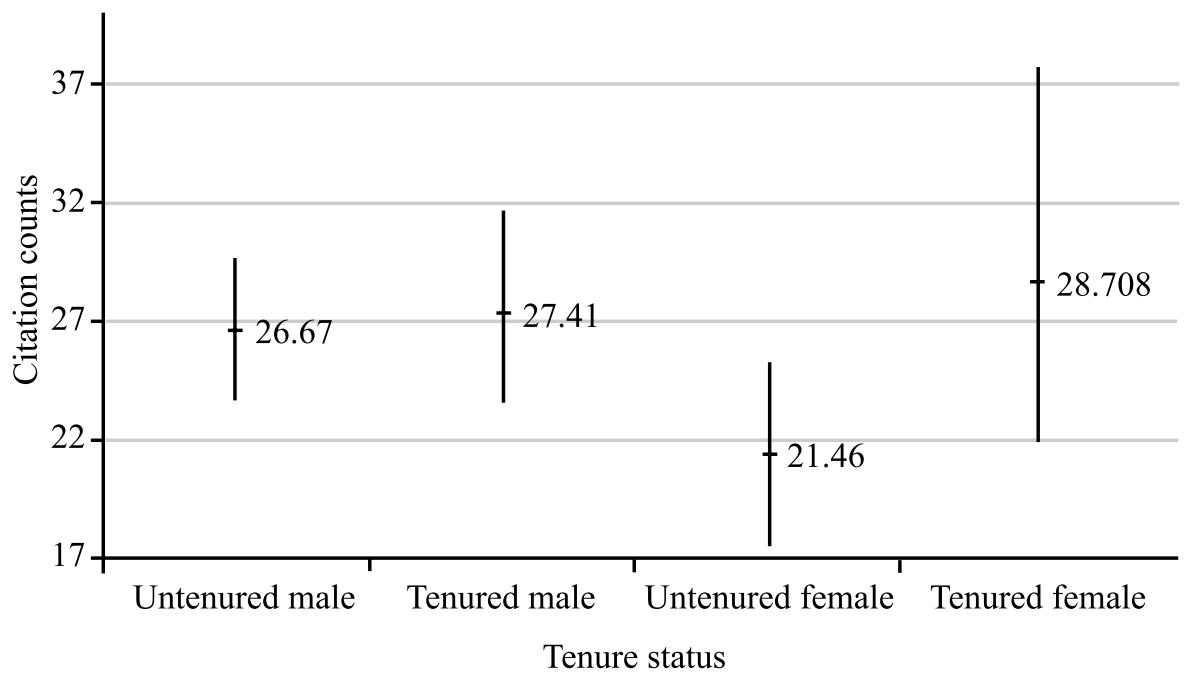

Notes: Estimates for single-authored articles by authors at R1 institutions. Estimates from career model.

FIGURE 1. Estimated citation counts with simulated confidence interval

The articles in our sample authored by women are more likely to employ a nonpositivist or postpositivist epistemology than those authored by men. When we include a dummy variable for whether the article is postpositivist or nonpositivist, as seen in the epistemology model (Model 4), positivist articles receive relatively more cites than similar non- or postpositivist articles. The coefficient on ALL FEMALE, however, remains negative and significant. The ideational model (Model 6) shows that neither accounting for the ideational variables nor a lack of material variables has a significant effect or changes the signs and significance of our coefficients of interest ALL FEMALE and TENURE.

42. Note too that coauthored articles are cited more than single-authored articles. If past findings are correct, and women coauthor articles more often than men do, the positive effect of coauthoring on citation counts may mask some of the citation gender gap. 
Controlling for the particular issue area that a given paper addresses decreases the magnitude of the coefficient on ALL FEMALE, but it remains significant at conventional levels. Including the paradigm of the article does not substantially affect the citation gender gap. Using realism as a base category, our paradigm model (Model 7) shows that atheoretic and Marxist articles tend to be cited relatively less, while constructivist articles have more citations. ${ }^{43}$ As Model 7 illustrates, again, our coefficients of interest remain relatively stable after accounting for the research methods employed in each article. Formal or quantitative methods have a positive effect on citation counts, while descriptive methods are associated with fewer article citations. We cannot account for the gender citation gap by controlling for the fact that women are more likely to employ qualitative methods.

Finally, we estimate a kitchen sink model (Model 10) in which we include all article characteristics in one model and control for potential venue-specific citation effects. When we include a variable for each of the twelve journals, the net effect is to decrease the magnitude of coefficient on ALL FEMALE, but to substantially increase the magnitude of the TENURE coefficient. Despite accounting for a wide variety of factors that might affect the number of citations a publication might receive, we cannot explain why gender remains negative and statistically significant. Articles authored by all women are cited systematically less than similar articles written by either all men or by men and women together.

Are these findings driven by a few highly cited, male-authored articles? When we exclude articles with three standard deviations above the mean of cites or more, our results are substantively similar. The coefficient on ALL FEMALE is always negative, with point estimates very close across specifications. The consistency of the effect across many specifications lends support to the general finding, as well as the result being a more general phenomenon across the distribution of articles. Of course, any subset of articles that garners fewer citations will decrease the chance of a gap being statistically significant thanks to information loss.

To illustrate the gender gap in a slightly different way, we create a model of citation counts built from the all-male authored articles only. If citations occur regardless of the authors' gender, a model that explains variance in citation counts should be equally predictive regardless of the gender of the authors. Using the career model from our analysis, we calculate the predicted number of citations for each article in our data set authored by women only or having at least one author from each gender.

A quick comparison between the average number of predicted citations for maleauthored articles and the actual number of citations shows that the model seems to be quite precise. As Table 3 shows, our model predicts that male-authored articles

43. While the TRIP categorization of articles in the feminist tradition would be under nonparadigmatic, we do not think they make up a large enough portion of those articles to account for the positive coefficient. Moreover, while female respondents to the 2011 TRIP survey are also slightly more likely to be constructivists than male respondents, we do not find that accounts for the gap. 
should receive 25.3 citations. In reality, they received 25.13. Next, we can use the MIXED GENDER articles to see if the coefficients from the model based on all-male authors do well to predict citations in this excluded group. In this case, a simple t-test shows that a 0.67 difference in the number of citations between the actual and predicted counts is not statistically significant.

TABLE 3. Predicted vs. actual citation counts

\begin{tabular}{lrcrr}
\hline & All male & All female & Coed & Total \\
\hline Predicted & 25.30 & 25.67 & 29.76 & 25.72 \\
Actual & 25.13 & 20.88 & 29.09 & 25.04 \\
Difference & -0.17 & -4.79 & -0.67 & -0.69 \\
Observations & 2541 & & & \\
\hline
\end{tabular}

The out-of-sample analysis illustrates our key counterfactual: Would the number of citations a given article received change if it were written by a man (or men) instead of a woman (or women)? Our all-male model predicts articles authored by only women should have 4.7 more citations than they actually received. Of course, as is the same with our previous results, we cannot be sure we have controlled for all the important confounding variables. Still, we find this result striking. Even controlling for a wide variety of confounds, articles written by women are cited less often at a statistically significant rate.

As a final robustness check, we apply propensity weighting, as suggested by Imbens for multivalued treatments. ${ }^{44}$ This method calls for first running a multinomial logit on the treatment variable, in our case the article's gender composition. We then use the inverse of the predicted probabilities as a weight for that article. In this sense, articles for which the model highly correlates with the gender composition (that is, can predict it well), are weighted less than those for which gender is not related to the covariates. We then run our same negative-binomial regression model but apply these weights. As Table A4 in the appendix shows, this method of matching further supports the consistency of the gender gap result. The coefficient on ALL FEMALE remains negative and significant.

\section{Is There Also an "Influence" Gap?}

Thus far, we have shown a robust relationship between the gender of authors and the total number of times their papers are cited. Putting aside this result, we won- 
der if the ideas and influence of articles authored by women in the field of IR are also being undervalued? To address this, we propose the use of network analysis as a better measure of the impact of female authors on the field. This additional analysis measures impact much better than a simple citation count. Network analysis not only incorporates how many citations an article gets but also whether an article is cited by more influential articles. It is far more important to be cited in a seminal article than it is to be cited in an obscure one.

To measure the relative influence of a given article we employ the widely used HITS algorithm developed by Kleinberg. ${ }^{45}$ HITS calculates a hub score and authority score for each node in the network. Kleinberg's method was developed to measure the relative importance of nodes in the world's largest "citation" network: the Internet. ${ }^{46}$ A given node garners authority by being linked to by other nodes. More weight is placed on a link from a node that itself is linked to by many other nodes. To put it in the parlance of citation analysis, an article that is cited by many widely cited articles will have a higher authority score than an article cited by many articles that themselves are only rarely cited.

Using the network of citations produced by the twelve journals in the TRIP article-coding database, we calculate the "authority" score for all articles cited by at least one other article in the largest cluster of articles. ${ }^{47}$ These values range from 0 to 1 , with 1 being the most highly authoritative article, and 0 having no authority. We take the largest value an article achieves in any year of its publication. In this sense, we are looking to see if an article ever becomes highly influential over the entire period of our sample.

Our results largely mimic those of the citation count models presented earlier. Articles written by female authors are not only being cited less, but authors of the most influential articles are citing them less often. Table 4 presents the results of similar models to those used in the citation analysis using ordinary least squares (OLS) models. ${ }^{48}$ In this sense, we should expect that the position of articles written by women is more to the periphery of the IR citation network.

This finding can be seen in Figure 2, which highlights authorship by gender across the network plotted in space. Each circle represents an article. The size of the circle is proportional to its authority score. Articles written by female author(s)

45. Kleinberg 1999. The HITS algorithm is perhaps better than degree centrality and is a form of eigenvector centrality that makes use of both inward and outward links in the network. See Fowler, Grofman, and Masuoka 2007; Fowler and Aksnes 2007; and Lupu and Voeten 2012.

46. In 1998, several researchers at Stanford developed an algorithm similar to Kleinberg's for use in ranking search engine results. Their method would eventually be known as Google PageRank.

47. The largest cluster is that group of articles within which one could get from any one article to any other via citations, and has the largest number of articles total. We use the largest cluster because our measure takes into account only those articles that have at least one tie to another, connected article. We cannot calculate a centrality value for those single articles or groups of articles that are unconnected to this largest cluster. By definition, the articles we lose are the most peripheral, since they are not cited by any articles in the largest cluster, and do not cite any of those within the largest cluster.

48. The results are robust to a number of other modeling choices, including the use of a tobit model. 


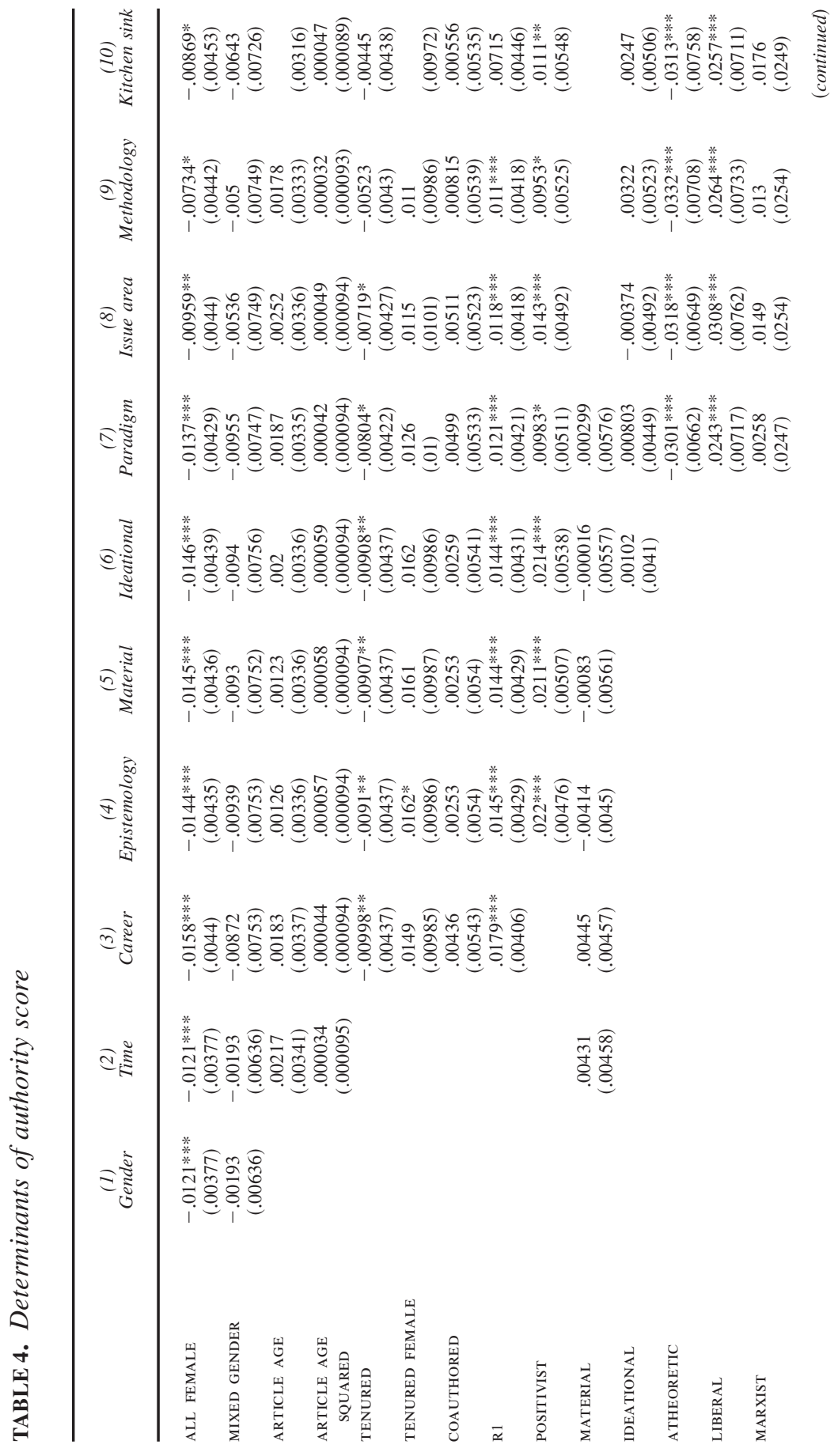









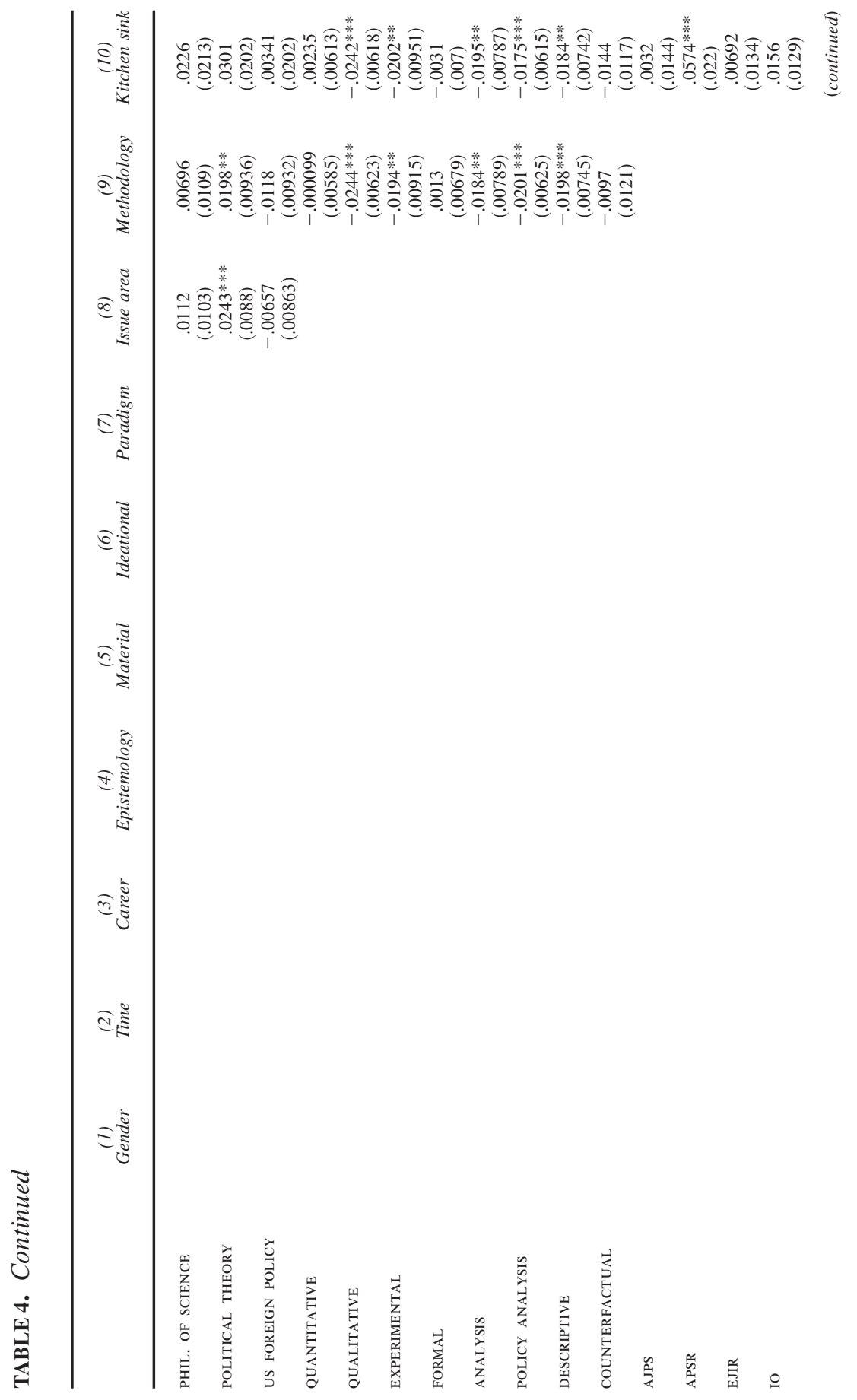




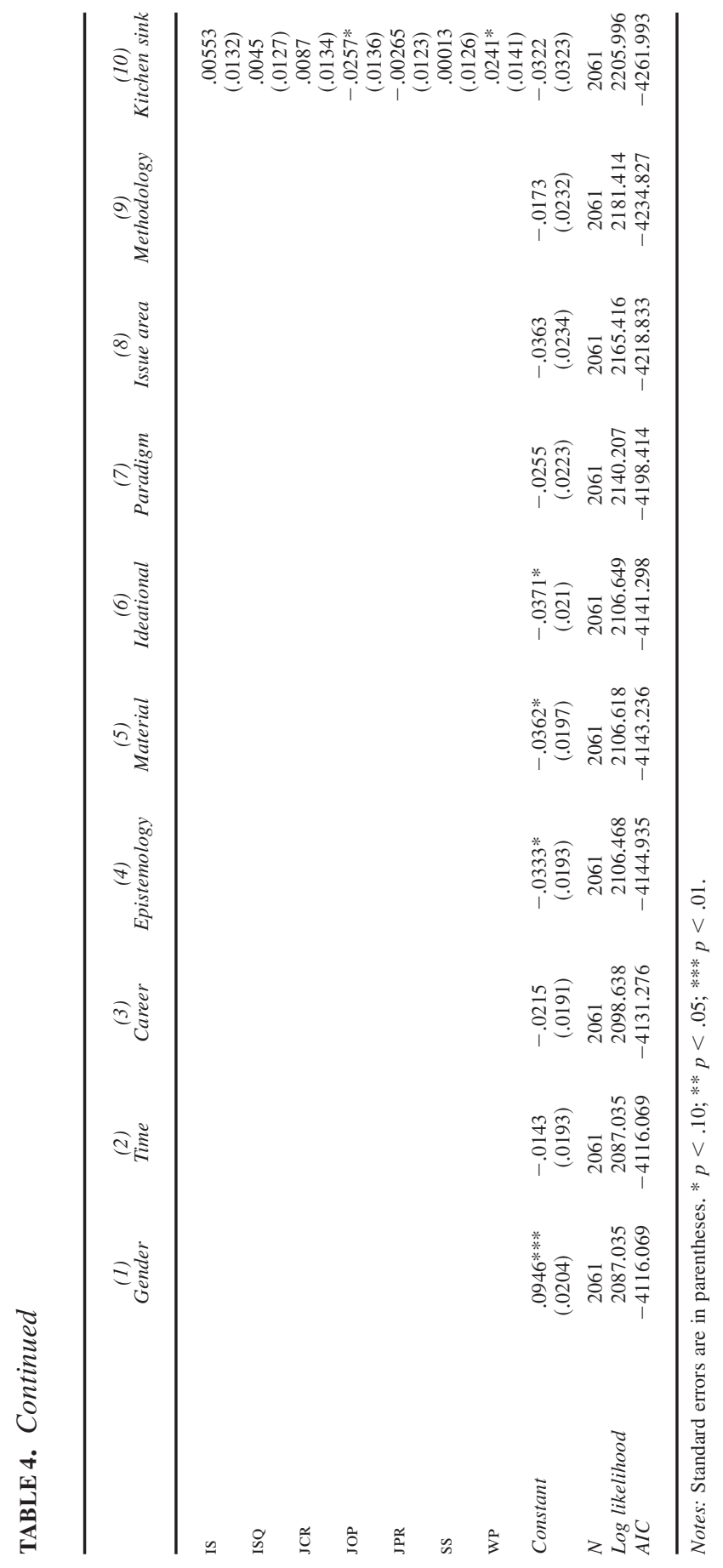


are colored green. Articles written by all men are blue, and those written by some combination of men and women are colored red. As you can see from Figure 2, the all-female nodes (green) are much smaller on average than the male (blue) and mixed gender nodes (red). The green nodes also tend to be smaller than their blue counterparts.

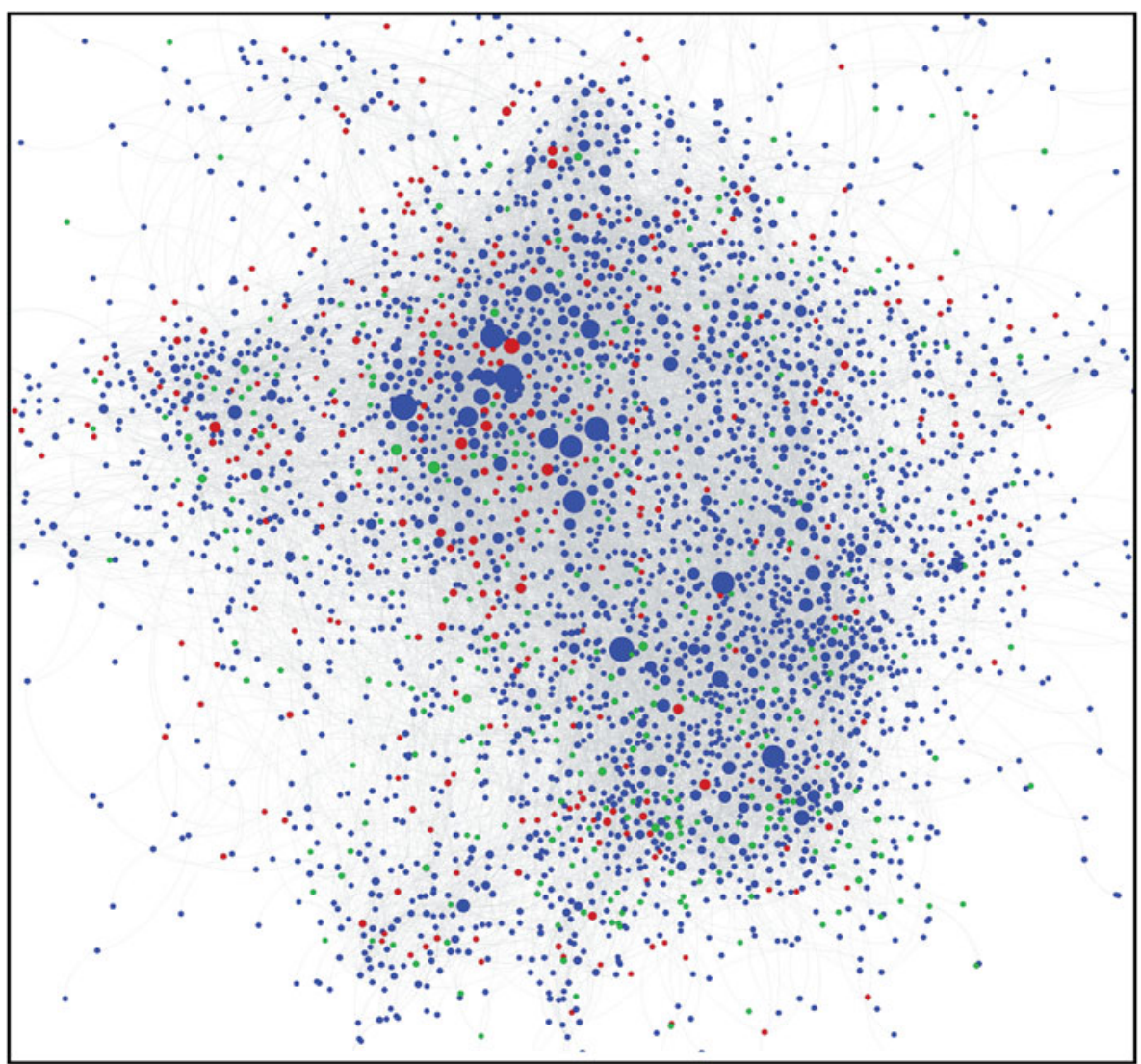

Notes: Green nodes are authored by all females. Blue nodes are authored by all males. Red nodes are authored by at least one male and at least one female. The size of the node is proportional to its HITS centrality score.

FIGURE 2. Visualization of citation network

\section{Is The Gap Getting Smaller Over Time?}

Readers will want to know if the gap is declining over time. If the field of IR is becoming more gender balanced, then it could be that younger female scholars 
will be disadvantaged less or not at all. To address this question, we estimate a slightly different version of our preferred model. Here we include an interaction between our all-female variable and the age of the article. ${ }^{49}$ Table A5 reports the results. Because of the multiplicative interaction term, the effect of all gender is not clear from simply looking at the table. Figure 3 plots the coefficient on allfemale as it changes over the range of the article-age variable. We see that older articles written by women are subject to greater bias than those written by men or coauthored with men. As we move from right to left on the graph, we see that the coefficient on all female declines in magnitude and eventually becomes statistically insignificant at conventional levels in more recent periods.

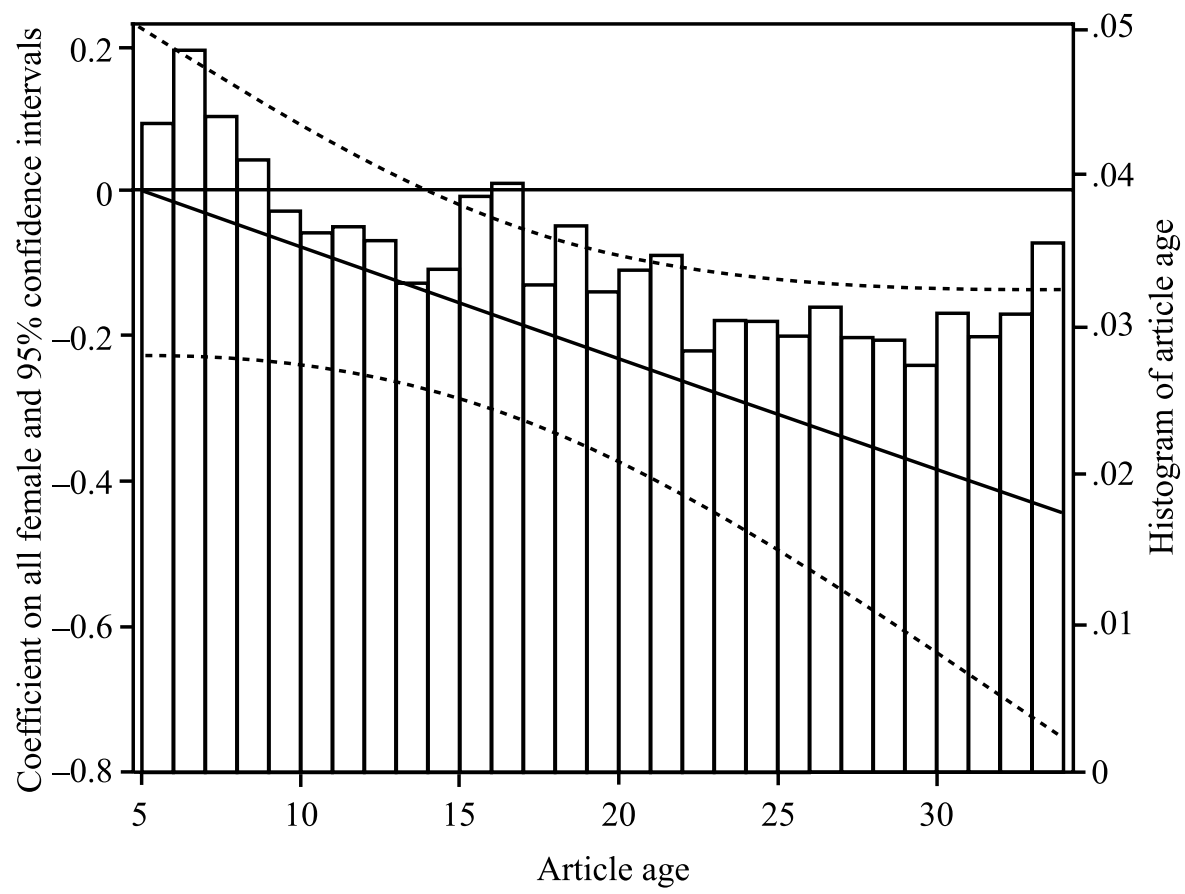

FIGURE 3. Coefficient on all female at different levels of article age

The most confident conclusion we can draw is that the gap is not statistically significant in the most recent periods. The lack of significance, however, is not tantamount to there being no gap. An optimist might argue this pattern illustrates the decline in the gender bias over time. But this result is consistent with the bias

49. For ease of interpretation, we omit the age-squared term and the tenured-female variable. 
in citation counts taking a number of years to be realized. In an attempt to discern between these two observationally equivalent but substantively different outcomes, we constructed two new dependent variables. The first is the cumulative number of citations that a given article has received when it is six years old, and the second is the authority score of a given article at six years. We choose six years because it is roughly the length of many tenure clocks and allows us to include most of our data, as a later year would result in dropped cases in the later part of our sample.

Table A6 in the appendix displays the results for cumulative citations as the dependent variable. We conduct subsample analyses by decade. Column (1) replicates the full sample analysis using our new dependent variable. Columns (2) to (4) report the results from our decade subsamples. We see from this analysis that in the 1980s, the coefficient is negative, statistically significant, and substantially larger than the coefficient for the full sample. In the 1990s and 2000s, the coefficient on all female is smaller in magnitude and, while it is negative, is no longer statistically significant. While one might take heart from these results, we caution that the insignificant finding in later decades means only that we cannot say the gap exists with certainty, and that the reduced sample because of the time constraint could be causing this result.

Table A7 in the appendix displays the results of our subsample analysis on the authority score at six years. Again, column (1) replicates our full sample analysis using our new dependent variable, while columns (2) to (4) report the results from our decade subsample analyses. In contrast to our cumulative citation count variable, we see that ALL FEMALE is negative and statistically significant across all models. While the coefficient is declining in magnitude over time, it is difficult to compare the coefficients across models, thus preventing us from saying that the gender bias in authority scores is, in fact, declining over time. In some respects, these results are more important to IR as a discipline because they are based on dyadic citation behavior within the IR literature, while the cumulative citations count is based on all citations recorded by WOK-whether from IR articles, political science in general, or other disciplines. While we are less sure about the magnitude of the gap in recent years, it does appear that women are still systematically less central in the IR citation network than are men.

\section{Other Explanations for the Citation Gap}

The data reveal that articles published by women in the top IR journals are cited less often than those written by men even after controlling for the age of publication, whether the author came from an R1 school, the topic under study, the quality of the publishing venue, the methodological and theoretical approach, and the author's tenure status. Articles written by women are cited less often than articles coauthored with at least one man. They are also cited less often in seminal articles in the field. This bias may or may not be declining, but even if it is, women's 
work is still not valued to the same degree as men's. This is a striking and disturbing pattern given the weight the profession assigns citation counts in evaluating scholars and their institutions.

\section{Women Cite Themselves Less Than Men}

If the obvious factors do not account for the citation gap, what does? It is possible that the gap in citation counts is the result of women failing to cite their own work as frequently as men do. Self-citation is the easiest way to increase one's citation count because the total number of citations any one article receives over the course of its lifetime is small. In fact, the average number of citations an article in the social sciences and humanities receives in a year is less than one..$^{50}$ The average number of total citations received by articles in the TRIP data set was twenty-five. Adding even one additional citation every year, therefore, quickly adds up.

Self-citation also appears to have a compounding effect. Fowler and Aksnes find that self-citation increases future citations from others, at least among the Norwegian scientists they studied..$^{51}$ In their study, each self-citation generated an additional 3.65 citations from others after ten years. Thus, even if promotion and review committees were to subtract self-citations from overall citation counts, there would still be a substantial benefit from citing oneself.

A look at our data reveals that women in IR do, in fact, cite their work significantly less than men. ${ }^{52}$ We begin by defining a self-cite as any citation that has a common author with the author of the published article. ${ }^{53}$ As Table 5 shows, among those single-authored articles, male-authored articles have 0.4 self-cites on average, while articles authored by one woman self-cite 0.25 articles. Looking at only coauthored articles reveals a similar pattern, where those written by two or more men cite themselves more than women. There is no significant difference between articles written by two or more men, and those written by at least one man and one woman. Again, we see that the introduction of one male author to the mix

50. Harzing 2010.

51. Fowler and Aksnes 2007.

52. Here we must rely on citation counts from within the network of top twelve journals tracked by the TRIP project. Recall that the dependent variable is the total number of times an article is cited in all of the journals tracked by the WOK. We are unable to collect information about the identity of each of these citations. We are, however, able to identify cases in which a given scholar in the TRIP database cites his or her own work elsewhere in the TRIP database. As such, our dependent variable here is the total number of times a scholar is cited by articles in the TRIP database minus the number of times a given author cites him- or herself in the TRIP database. The correlation between the number of citation counts from WOK and citation counts just from articles within the TRIP database is greater than 80 percent.

53. Although it is possible that a larger portion of women's research is published outside these twelve journals where women might be citing themselves at the same rate as men, we assume that the citations within this network closely mirror those overall. Because we cannot test this proposition, one should consider these results with this proviso in mind. 
causes articles to "look" more like male-authored articles. ${ }^{54}$ In both cases, the difference is substantively large, being just under 40 percent more in single-authored work, and more than double in coauthored work.

TABLE 5. T-test comparing self-citations among author gender

\begin{tabular}{llcr}
\hline Group & Mean & $\begin{array}{c}\text { Standard } \\
\text { deviation }\end{array}$ & $\begin{array}{c}95 \% \\
\text { confidence interval }\end{array}$ \\
\hline $\begin{array}{l}\text { Single-authored } \\
\quad \text { Men }\end{array}$ & 0.40 & 0.02 & $0.37-0.43$ \\
$\quad$ Women & 0.25 & 0.03 & $0.19-0.31$ \\
$\quad$ Difference & $0.15 * * *$ & 0.04 & $0.07-0.24$ \\
Coauthored & & & \\
$\quad$ Men & 0.91 & 0.04 & $0.83-1.00$ \\
Women & 0.41 & 0.16 & $0.08-0.74$ \\
Difference & $0.50^{* *}$ & 0.24 & $0.03-0.97$ \\
Men & 0.91 & 0.04 & $0.83-1.00$ \\
Mixed gender & 0.89 & 0.06 & $0.77-1.01$ \\
Difference & -0.02 & 0.08 & $-0.17-0.13$ \\
\hline
\end{tabular}

Notes: $* * p<.05 ; * * * p<.01$.

Does controlling for self-citation have a major effect on the gap? Here, we take the number of citations within our twelve-journal network and subtract all selfcitations. Using this new citation count as the dependent variable, we find that the gender gap still exists. Articles written by women still receive fewer citations than those written by men. Moreover, as we suspected, coed-authored articles do not differ statistically from male-authored articles. The coefficients from models that do and do not account for self-citation do not differ statistically from each other.

The fact that the gender gap in citations continues even when we remove selfcitations from the analysis is not surprising. If one self-citation translates into almost four additional citations, as Fowler and Aksnes found, then removing the selfcitations will not correct for this additional benefit. ${ }^{55}$ To address this, we not only subtract all self-citations from the total number of citations an article receives, but we also subtract an additional 3.65 citations for each self-cite. ${ }^{56}$ When we control

54. This gender gap persists when we conduct additional analysis that controls for the number of authors.

55. Fowler and Aksnes 2007.

56. One challenge, however, exists. For those articles that have three or less citations, and where one or more is a self-cite, the value turns negative when we subtract 3.65. Since we cannot have negative citations, we code these cases as having zero citations. 
for "bonus" citations, the results still hold. Articles written solely by women are still cited significantly less than those written by men. Thus, although self-citation may explain some of the discrepancy between men and women, it does not explain all.

\section{The Existence of Citation Groups}

The second possible explanation has to do with informal agreements made among a group of scholars to cite each other. Clusters of individuals could inflate their citation counts by agreeing to cite each other in every article they write even if their research is only tangentially related. One type of citation game is the citation cartel. Here, groups of editors at academic journals have been known to collude to publish review articles that heavily cite articles published in each others' journals as a way to improve their impact factor. ${ }^{57}$ This type of behavior is not only an easy way to increase citations, but it is also more difficult to trace than selfcitations. If men are more apt to form such alliances than women, or have more opportunity to do so given their larger numbers or more extensive social networks, then this informal collaboration could account for the higher rate of citations for men.

We have no definitive evidence that such informal arrangements exist or that they are more prevalent among men than women. However, stories abound in the halls of academia of such groups forming between graduate-student friends, or subfield cohorts. The evidence we do have reveals that citations appear to split along gender lines. Men tend to cite male-authored articles more than femaleauthored articles and women tend to cite female-authored articles more than maleauthored articles. ${ }^{58}$ This difference alone could account for the gender gap in citations since the number of men in IR is significantly higher than women. If IR scholars tend to cite along gender lines, which Table 6 suggests they do, then any researcher who is male will get a boost in citation counts simply for being a member of the dominant gender.

\section{Conclusion}

These powerful findings reveal that articles written by women in IR are cited less than men even after controlling for a wide range of factors. A research article written by a woman and published in any of the top journals will still receive significantly fewer citations than if that same article had been written by a man.

57. Franck 1999.

58. This supports Mitchell, Lange, and Brus (forthcoming), whose study of articles published in $I S Q$ and $I S P$ finds that women were three times more likely to cite the work of other women compared with all-male or mixed-gender teams. 
TABLE 6. Dyadic citations by gender, percentages represent the mean for all articles of each type

\begin{tabular}{lrccc}
\hline Type citing & All articles & Male-authored & Female-authored & Coed-authored \\
\hline All male citing & $71.07 \%$ & $75.00 \%$ & $59.60 \%$ & $63.17 \%$ \\
All female citing & $9.62 \%$ & $8.65 \%$ & $18.56 \%$ & $10.03 \%$ \\
Coed citing & $10.92 \%$ & $9.63 \%$ & $14.96 \%$ & $18.21 \%$ \\
\hline
\end{tabular}

We do not believe the citation gap will go away on its own even if it might improve over time. In fact, these findings make five things clear. First, citation counts are not a fair and objective measure of the quality and impact of a scholar. We now know that women will have lower citation counts than their male colleagues, at least into the foreseeable future, all else equal. Moreover, the bias stems not from a difference in quality, topic, or choice of research strategy but from certain underlying behaviors (fewer self-citations by women, and more withingender citations).

Second, self-promotion strongly affects citation counts and women are less likely to promote themselves. Not only does self-citation increase one's overall citation score, but it also exposes one's work to a larger number of scholars, exponentially increasing citations. The fact that citation counts can be manipulated, and that this strategy is more apt to be pursued by men, disadvantages women.

Third, scholars tend to cite work by scholars of the same gender. This does not necessarily pose a problem for citation counts if a field has a fairly equal number of male and female scholars. If, however, a field is heavily dominated by men, as is the case in IR, then this pattern will lead to significantly fewer citations for women and significantly less exposure for their scholarship. It also means that the gap is not likely to disappear until a more equal number of male and female researchers exists. ${ }^{59}$

Fourth, networks matter. Producing high-quality work is not sufficient for research to gain the attention of the widest number of scholars or have the greatest impact. Scholars tend to cite scholars they know, and work produced by lesserknown scholars, or scholars in small or peripheral networks, is likely to be cited less. If networks tend to bifurcate along gender lines, then any field that is disproportionately male will also disproportionately favor their work.

59. Ferber and Brün (2011) found that the gender citation gap significantly decreases when women constitute a critical mass in the discipline. 
Finally, this study reveals that a subset of scholarship in IR is being systematically undervalued, even if inadvertently. ${ }^{60}$ Research produced by a woman will be read less and cited less than research produced by a man. Not only does this mean that the trajectory of intellectual developments will be slower than it should be, but it means that the types of topics and methods being showcased in journals and on syllabi are likely to be skewed toward those favored and pursued by men.

The implications of this gap are potentially large. If citation counts, such as the h-index, are the main means by which review committees measure productivity and impact, then women will not gain tenure at the same rate as men, they will not be promoted at the same rate as men, and they will not be offered comparable salaries to men. This may help explain why women represent such a small percentage of tenured faculty, especially at major research universities. Understanding that a bias exists, therefore, is a first step in improving gender diversity in the make-up of the academic community.

This study suggests a variety of things faculty, department heads, and journal editors can do to reduce the gap. For faculty, three strategies are likely to be helpful. First, faculty can inform all of their students (especially female students) of the value of self-citation. If self-citation is a common and conventional practice, and we know it is, then women need to be encouraged to advocate for themselves and their work. As Fowler and Aksnes discovered, there are no penalties even for the most egregious self-citation. ${ }^{61}$ In a world where the absolute number of citations an article receives is low and where citations can mean the difference between promotion or none, the failure to cite oneself can be professionally harmful. Second, faculty should also make female students aware of the benefits of coauthorship across gender lines since collaboration may be one way to increase the visibility of one's scholarly work. We do not think this should be a call for researchers to choose their coauthors based on anything but research abilities and collaborative qualities. Still, the real advantages of coauthoring should be known. Finally, faculty can emphasize the value of networking by helping their students make connections, especially with powerful members of the field. This is especially important for women in a field that is disproportionately dominated by men.

The most important recommendation for departments is to take the existence of gender bias seriously when evaluating female scholars for promotion and review. One could argue that citations should no longer be used as a measure of scholarly impact or weighted as heavily as they have been. Any measure that has been shown to include significant bias and is easy to manipulate should be discarded in favor of other, better measures. We do not believe this is the best path to take. Citation counts are a biased measure of quality and impact, but-as we demonstrated above-this bias is quantifiable to a significant degree. We believe it is better to

60. See also Kadera 2013.

61. Fowler and Aksnes 2007. 
work with an existing indicator whose bias is known, than to switch to one that is assumed to be unbiased but is not.

The findings also suggest that departments will need to determine whether bias exists in the other subfields as well. One of the questions that is likely to come up in department meetings is whether this finding is unique to IR or more widespread. It is possible, for example, that IR is a more "masculinized" subfield because of its connections with the foreign policy world or because a greater proportion of IR scholars are male. While it is possible that IR is disproportionately affected by this problem, we do not believe this is likely to be the case. Additional research will be needed to determine whether this is true, but until then, departments will need to consider that other subfields may be affected as well.

This research suggests ways in which editors at academic journals might help reduce the gap. One of the fascinating findings to emerge from this study is the tendency for men and women to more heavily cite authors from their own gender. A large portion of the gender citation gap, therefore, could be narrowed if men and women were made aware of this pattern and encouraged to be more gender neutral in who they choose to cite. One suggestion for editors is simply to monitor the ratio of male to female citations in the articles they publish. ${ }^{62}$ What if reviewers took note of the gender ratio of citations and pointed this out to authors when citations are heavily skewed in favor of one or the other gender? Simply making authors aware of this tendency and identifying it when it occurs could help narrow the gap.

Some of the factors we discuss may be relatively easy to fix-such as the tendency for women in IR to cite themselves less. Some will be more difficult to fix - such as the tendency of individuals to cite members of their own gender. All require additional research to understand why these patterns exist and why individuals behave this way. This article says nothing about other systematic ways in which women might be disadvantaged in IR and in academia more generally. A similar study, for example, has not yet been done on whether a gender bias exists in hiring and promotion, or whether a bias exists in rates of submission and acceptance at top journals. Are articles written by women treated differently in the publication review process? Until we know the full range of bias that exists, it will be difficult to fully reach gender parity on campuses across the country.

Our first hope is that this study serves as a catalyst for additional research into the subtle and not-so-subtle barriers that may stand in the way of women rising through the ranks in any field historically dominated by men. We also hope that it helps pave the way for real changes in how universities mentor, support, and promote women. We are not the first to talk about bias in academia. The challenge has always been to prove that it exists. This study shows that it exists in at least one area related to women's advancement in the field: citations. If colleges and

62. Some journals already do this. 
universities are serious about increasing the number of women on campuses, then this research reveals one area ready for improvement.

\section{References}

American Political Science Association (APSA). 1992. Improving the Status of Women in Political Science: A Report with Recommendations. PS: Political Science and Politics 25 (3):547-54.

— 2004. Report of Workplace and Family Issues Subcommittee. Available at 〈https://www .apsanet.org/imgtest/APSAReportofWorkplace\&FamilyIssuesSubcmt2.pdf $\rangle$. Accessed 8 May 2013.

- 2007. Data Snapshot: The Proportion of Women in the Political Science Profession. Available at $\langle$ https://www.apsanet.org/imgtest/Website\%20brief\%20on\%20women\%20in\%20PS\%20v2\%20 1\%202007.pdf $\rangle$. Accessed 8 May 2013.

Breuning, Marijke, Joseph Bredehoft, and Eugene Walton. 2005. Promise and Performance: An Evaluation of Journals in International Relations. International Studies Perspectives 6 (4):447-61.

Büthe, Tim, and Vinod Aggarwal. 2013. Citation Counts: Measuring Impact in the Social Science. Unpublished manuscript, Duke University, Durham, N.C., and University of California, Berkeley.

Charles, Maria, and David B. Grusky. 2005. Occupational Ghettos: The Worldwide Segregation of Women and Men. Stanford, Calif.: Stanford University Press.

Copenheaver, Carolyn A., Kyrille Goldbeck, and Paolo Cherubini. 2010. Lack of Gender Bias in Citation Rates of Publications by Dendrochronologists: What Is Unique About This Discipline? TreeRing Research 66 (2):127-33.

Dries, Nicky, Roland Pepermans, and Olivier Carlier. 2008. Career Success: Constructing a Multidimensional Model. Journal of Vocational Behavior 73 (2):254-67.

Ferber, Marianne A., and Michael Brün. 2011. The Gender Gap in Citations: Does It Persist? Feminist Economics 17 (1):151-58.

Finifter, Ada W. 1973. The Professional Status of Women Political Scientists: Some Current Data. PS: Political Science and Politics 6 (4):406-19.

Fisher, Bonnie S., Craig T. Cobane, Thomas M. Vander Ven, and Francis T. Cullen. 1998. How Many Authors Does It Take to Publish an Article? Trends and Patterns in Political Science. PS: Political Science and Politics 34 (4):847-56.

Fowler, James H., and Dag W. Aksnes. 2007. Does Self-Citation Pay? Scientometrics 72 (3):427-37.

Fowler, James H., Bernard Grofman, and Natalie Masuoka. 2007. Social Networks in Political Science: Hiring and Placement of PhDs, 1960-2002. PS: Political Science and Politics 40 (4): 729-39.

Franck, Georg. 1999. Scientific Communication: A Vanity Fair? Science 286 (5437):53-55.

Ginther, Donna K. 2004. Gender Differences in Salary and Promotion in Political Science. Paper presented at the American Political Science Association workshop on "Women in the Profession," March, Washington, D.C.

Gruberg, Martin, and Virginia Sapiro. 1979. Participation by Women in Annual Meetings, 1970-78. PS: Political Science and Politics 12 (3):318-24.

Harzing, Anne-Wil. 2010. The Publish or Perish Book: Your Guide to Effective and Responsible Citation Analysis. Melbourne, Australia: Tarma Software Research.

Hesli, Vicki L., Jae Mook Lee, and Sara McLaughlin Mitchell. 2012. Predicting Rank Attainment in Political Science: What Else Besides Publications Affects Promotion? PS: Political Science and Politics 45 (3):475-92.

Hix, Simon. 2004. A Global Ranking of Political Science Departments. Political Studies Review 2 (3):293-313.

Imbens, Guido W. 2000. The Role of the Propensity Score in Estimating Dose-Response Functions. Biometrika 87 (3):706-10. 
Kadera, Kelly M. 2013. The Social Underpinnings of Women's Worth in the Study of World Politics: Culture, Leader Emergence, and Coauthorship. International Studies Perspectives.

King, Gary, Robert O. Keohane, and Sidney Verba. 1994. Designing Social Inquiry: Scientific Inference in Qualitative Research. Princeton, N.J.: Princeton University Press.

Kleinberg, Jon M. 1999. Authoritative Sources in a Hyperlinked Environment. Journal of the ACM 46 (5):604-32.

Long, J. Scott. 1992. Measures of Sex Differences in Scientific Productivity. Social Forces 71 (1):159-178.

Lupu, Yonatan, and Erik Voeten. 2012. Precedent on International Courts: A Network Analysis of Case Citations by the European Court of Human Rights. British Journal of Political Science 42 (2):413-39.

Maliniak, Daniel, Amy Oakes, Susan Peterson, and Michael J. Tierney. 2007. The View from the Ivory Tower: TRIP Survey of IR Faculty in the United States and Canada. Available at $\langle$ http://www.wm.edu /offices/itpir/_documents/trip/ivory_tower_view_2007.pdf). Accessed 8 May 2013.

—. 2008. Women in International Relations. Politics and Gender 4 (1):122-44.

2011. International Relations in the US Academy. International Studies Quarterly 55 (2):437-64.

Maliniak, Daniel, Susan Peterson, and Michael J. Tierney. 2012. TRIP Around the World: Teaching, Research, and Policy Views of International Relations Faculty in Twenty Countries. Available at $\langle$ http://www.wm.edu/offices/itpir/_documents/trip/trip_around_the_world_2011.pdf $\rangle$. Accessed 8 May 2013.

Mitchell, Sara McLaughlin, Samantha Lange, and Holly Brus. Forthcoming. Gendered Citation Patterns in International Relations Journals. International Studies Perspectives.

Østby, Gudrun, Håvard Strand, Nils Petter Gleditsch, and Ragnhild Nordås. Forthcoming. Gender Gap or Gender Bias in Peace Research? A Study of Publication Patterns and Citation Rates for Journal of Peace Research, 1983-2008. International Studies Perspectives.

Peñas, Celia Sánchez, and Peter Willett. 2006. Brief Communication: Gender Differences in Publication and Citation Counts in Librarianship and Information Science Research. Journal of Information Science 32 (5):480-85.

Peterson, Susan, and Michael J. Tierney. 2010. Codebook and User's Guide for TRIP Journal Article Database. Available at 〈https://mywebspace.wisc.edu/rpowers/files/trip_codebook_2010.pdf $\rangle$. Accessed 8 May 2013.

Schuck, Victoria. 1969. Women in Political Science: Some Preliminary Observations. PS: Political Science and Politics 2 (4):642-53.

Slyder, Jacob B., Beth R. Stein, Brent S. Sams, David M. Walker, B. Jacob Beale, Jeffrey J. Feldhaus, and Carolyn A. Copenheaver. 2011. Citation Pattern and Lifespan: A Comparison of Discipline, Institution, and Individual. Scientometrics 89 (3):955-966.

Sonnert, Gerhard. 1995. What Makes a Good Scientist? Determinants of Peer Evaluation Among Biologists. Social Studies of Science 25 (1):35-55.

Sonnert, Gerhard, and Gerald Holton. 1996. Career Patterns of Women and Men in the Sciences. American Scientist 84 (1):63-71.

Symonds, Matthew R.E., Neil J. Gemmell, Tamsin L. Braisher, Kylie L. Gorringe, and Mark A. Elgar. 2006. Gender Differences in Publication Output: Towards an Unbiased Metric of Research Performance. PLoS ONE 1 (1):e127. Available at 〈http://www.plosone.org/article/info\%3Adoi\%2F10 $.1371 \% 2$ Fjournal.pone.0000127〉. Accessed 8 May 2013.

US Department of Education. 2011. Digest of Education Statistics 2010, NCES 2011-015. Washington, D.C.: National Center for Education Statistics. 